\author{
Amalia Bosch Benítez \\ Universidad de Las Palmas de Gran Canaria \\ amalia.bosch@ulpgc.es
}

\title{
ESTUDIO DE LA CORRESPONDENCIA ENTRE PÉREZ GALDÓS Y SUS TRADUCTORES AUSTRIACOS
}

DOl: http://dx.doi.org/10.12775/RP.2020.005

Resumen: En un artículo de próxima publicación (Bosch, 2020) estudiamos la relación epistolar que el escritor, Benito Pérez Galdós, mantuvo en vida con personas que solicitaban el honor de traducir sus novelas y dramas al alemán. En aquella ocasión nos ceñimos a la correspondencia con traductores alemanes. En esta nueva aportación, continuamos escudriñando la dimensión universal del escritor canario a través de la correspondencia con sus traductores austriacos.

Palabras clave: Galdós, translators, Austria, correspondence

\section{Introducción}

En el archivo de la Casa-Museo Pérez Galdós, en Las Palmas de Gran Ca-naria, se conserva la correspondencia que el escritor sostuvo en vida con diferentes personas del mundo empresarial, editorial, político, cultural, periodístico, etc. del siglo XIX y XX, además de con su familia y amigos.

La correspondencia con el escritor procede de, prácticamente, todos los países, pero nosotros nos centramos en Europa, más concretamente, en Austria. Aunque no se conserve absolutamente toda la correspondencia, el dinamismo en el carteo del escritor con personas o entidades del ámbito político, cultural y literario de todo el mundo, da una idea de la dimensión universal de Galdós. Ahora bien, y que nosotros tengamos constancia, no se ha publicado aún un epistolario entre Galdós y sus traductores. Estas cartas existen, 
y fruto de esa relación epistolar se tradujeron al francés, al inglés, al neerlandés, al alemán, etc. algunas de las obras del insigne escritor.

Nuestro objetivo central iba encauzado a realizar un análisis históricotraductológico del interés de la obra de Galdós a través de esas cartas. Utilizamos el epistolario con personas que le escribían para obtener los derechos de traducción de sus obras. Es el contenido de estas cartas con aquellos traductores las que arrojan la prueba del interés que suscitó la literatura de Galdós, en Austria. De esta manera, una literatura escrita en español, se convirtió en literatura universal, pues es una realidad que sin traductores la obra de muchos escritores no traspasaría las fronteras nacionales.

La carta, tradicionalmente, ha sido estudiada por la literatura y las humanidades como género literario. Sin embargo, es en primer término una "fuente histórica":

Ursprünglich und in erster Linie ist der Brief eine historische Quelle, zu einer literarischen Gattung kann er erst werden, wenn er eine bestimmte sprachliche und stilistische Qualität erreicht (Krauße 2005: 11)1.

La historiografía utiliza fuentes documentales, como pueden ser los diarios o las cartas, como instrumentos auxiliares para el estudio de la sociedad de una época concreta. Existen varios tipos de carta y el género está aún por definir (Krauße 2005). Las hay de tipo privado, de valor científico, literario etc. $y$, en este caso, hemos elegido un tipo de carta a medio camino entre lo personal y lo empresarial. Galdós gestionaba sus asuntos editoriales y respondía a las cartas recibidas de periódicos, teatros o traductores, y en este tipo de carta, muy alejado de lo que consideraríamos cartas de índole privado, se engloban las que hemos analizado en este artículo.

El estudio del epistolario ha constatado que la carta en sí misma se convierte, por lo tanto, en un documento histórico de interés científico para los investigadores de la historia de la traducción. Constituye una fuente primaria muy útil, pues vierte luz sobre diferentes aspectos de la sociedad del siglo XIX y XX. En ellas se recogen entre otros asuntos, contratos entre directores de teatros y el escritor para la representación y traducción de sus obras; condiciones contractuales en las que figuran plazo y retribución económica, muy habituales para los traductores de la época; nos permiten comparar el

${ }^{1}$ Orig.: "La carta es, inicial y principalmente, una fuente histórica y sólo podrá ser adscrita al género literario si alcanza una calidad estilística notable desde un punto de vista lingüístico" [traducción propia]. 
mundo editorial de la época con la realidad actual; nos informan de quiénes se atrevían a abordar la traducción de literatura escrita en español y qué conocimientos o formación tenían; nos enteramos de que había unas versiones traducidas, de muy mala calidad, que imposibilitaron, en algunos casos, la representación teatral de la obra; y se nos informa de otros muchos aspectos en torno a la actividad ligada a la literatura en el siglo XIX y XX como la censura, los derechos de autor, la publicación en gacetas o suplementos literarios, etc. Todo ello es de notable interés, no solo para completar ciertas lagunas en la bibliografía galdosiana, sino que también es de relevancia para la historia de la traducción.

Con este estudio histórico de la correspondencia entre Galdós y sus traductores austríacos hemos procedido de igual manera que hicimos con el estudio de las cartas recibidas desde Alemania y que hemos analizado en el artículo que, próximamente, se publicará en el número 2 de la revista Tibón. En primer lugar, solicitamos a la Casa Museo Pérez Galdós la correspondencia procedente de Austria. Las cartas no están disponibles para el público en general y solo previa solicitud a la institución se nos facilitó un PDF con esas epístolas ya digitalizadas. Son un total de 36 cartas remitidas por diferentes personas interesadas en traducir al alemán la obra de Galdós. Pero Austria, en el siglo XIX era un imperio que agrupaba a Hungría, a Chequia y a Eslovaquia, y existen cartas en las que se propone traducir al checo alguna novela. No son el objetivo central de nuestro análisis, pero surgen, inevitablemente, porque Austria, política y geográficamente, se extendía más allá de las fronteras de la ciudad de Viena y en el Imperio se hablaban diferentes lenguas. Pero como decimos, nos ocuparemos solo de las traducciones al alemán, no al checo ni al húngaro.

La existencia de estas cartas pone de relieve que el nombre de Galdós como escritor de novela y de teatro era conocido por parte de la prensa europea, y que la prensa europea estaba al tanto de los estrenos de las obras de teatro de Galdós o de la publicación de sus novelas. Se conservan telegramas entre el escritor e importantes teatros europeos para garantizarse los derechos de representación y traducción de sus piezas teatrales; telegramas que, prácticamente, se recibían al día siguiente del estreno de alguna de esas obras en Madrid, lo que da idea del dinamismo empresarial por parte de los directores de los teatros de la época y de cómo funcionaban las artes escénicas.

Como decíamos, el escritor recibe cartas de personas que se ofrecen para traducir su literatura. Si bien es cierto que algunos investigadores han reseñado la existencia de estas cartas, lo han hecho para ilustrar, exclusivamente, aspectos literarios o para analizar la calidad de las traducciones o la recepción 
de las obras de Galdós, como sucede con las novelas traducidas en Alemania (Ramírez Jáimez 1993, 1995, Siemers 1993).

Otros investigadores (López Jiménez 1990, 1993, 1995, Bly 2009) analizan las traducciones al francés y las traducciones al inglés, respectivamente, y para este fin utilizan, también como hemos hecho nosotros, la correspondencia con sus traductores. Algunos autores han investigado el impacto periodístico que de la obra de Galdós se tenía en Francia (Pinacho 2016) a través de su presencia en artículos en prensa, más concretamente en Le Temps. Otro investigador, Peter Bly (2009) analiza la prensa y la crítica que recibió Galdós por parte de los críticos europeos, pero, ninguno de ellos ha abordado el epistolario como un fin en si mismo.

Nosotros hemos utilizado una metodología historiográfica, utilizando la carta como fuente principal o primaria y, al hacerlo, hemos detectado la existencia de obras traducidas en Austria que eran desconocidas, hasta la fecha, en los estudios bibliográficos que habíamos consultado. No era un objetivo central de nuestro trabajo, pero surge, inevitablemente, al considerar la carta como fuente de información histórica. Esas carencias, en parte, pueden completarse gracias al estudio que hoy aportamos, pues el análisis de estas cartas nos ha permitido descubrir si tras esa relación epistolar cristalizó o no la traducción de alguna obra de don Benito.

\section{Estructura del trabajo: organización del material consultado}

Nuestro estudio abarcará una correspondencia que se extiende desde 1891 hasta 1910, es decir, un total de diecinueve años y un total de 36 cartas. Son bastantes menos que las que se conservan de corresponsales alemanes, pero igual de interesantes. Destaca una de las traductoras, Ellen Goldenberg, por el número de cartas - doce en total -, y por el número de traducciones que pubicó en prensa.

Como hemos avanzado, manejamos un PDF que contiene la correspondencia digitalizada por la propia Casa-Museo Pérez Galdós. La institución las digitalizó respetando un estricto orden alfabético, no cronológico. A la hora de referenciar las cartas en nuestro trabajo, hemos utilizado dos datos para identificarlas: en primer lugar, la fecha en que está escrita, (carta de fecha ...) $\mathrm{y}$, en segundo lugar, un número correlativo de orden (carta número ...). Este número es el que se despliega, por defecto, en el documento digitalizado y coincide con la paginación de este archivo digital. Lo hemos aprovechado para adjudicar un número a las cartas. Es decir, si referenciamos una de ellas 
como «carta número 132» estaremos, simplemente, utilizando el número de orden natural que se corresponde con la página del archivo en PDF, no a un índice documental específico, que no existe. Y además la dataremos cronológicamente, porque tendrá una fecha que nos ayuda a ordenar la correspondencia.

Hemos preferido agrupar las cartas por contenido temático y no por orden alfabético. El tema coincidirá con la novela u obra teatral que el remitente desea traducir. Nos ha parecido que con este método se conseguía una mayor claridad para el lector. Es decir, si hemos encontrado cartas de corresponsales deseosos de traducir la novela Doña Perfecta, este será el título temático del epígrafe y dentro de él encontraremos un listado de los remitentes. De haber procedido de manera exclusivamente cronológica o alfabética habría un desorden temático que en nada contribuiría a ilustrar los objetivos de este estudio. Dentro de cada apartado temático sí se guarda un orden cronológico. Tendremos también en cuenta que, a veces, los corresponsales no elegían qué obra traducir, sino que dejaban a criterio de Galdós su selección; esa circunstancia se recoge en el epígrafe titulado Miscelánea.

\section{Los traductores y traducciones de Galdós al alemán: Austria}

Los traductores, cuyas cartas hemos analizado, se interesan, fundamentalmente, por algunas de las siguientes obras galdosianas: Doña Perfecta, Miau, El abuelo, La campaña del Maestrazgo, La novela en el tranvía, La mula y el buey, La de San Quintín, Electra, Alma y vida, Nazarín y Marianela.

En la bibliografía de Galdós (Hernández Suárez 1972) no consta que haya aparecido alguna traducción o publicación en Austria de Doña Perfecta (1876), Miau (1888), El abuelo (1897), La campaña del Maestrazgo (1899), La novela en el tranvía (1871), La mula y el buey (1876), Electra (1901) ni tampoco de Alma y vida (1902). Existen traducciones al checo de Marianela que se hizo en vida del autor (1904), y otra posterior de 1936 (Hernández Suárez 1972: 71). Pero no existen traducciones al alemán en Austria, según esta bibliografía. Lo mismo sucede con Doña Perfecta, de la que existe una primera traducción al checo de 1936 y las otras dos son de la década de los cincuenta (Hernández Suárez 1972: 45). Tanto checos como húngaros eran parte del Imperio y en algún caso, como el de Hugo Kosterka (carta número 64) que se interesa por traducir Doña Perfecta, no queda del todo claro en su carta si quiere traducir al checo o al alemán. El dato es interesante, pero no cambia el hecho de que tampoco aparece como traductor de esa obra en la bibliografía 
de Hernández Suárez. García Bolta (1993) recoge en su artículo las traducciones al húngaro de Gloria, Misericordia y Doña Perfecta, pero tampoco reseña Austria en su trabajo. Bly (2009) solo recoge la traducción y publicación de Electra por parte de Rudolf Beer en una editorial vienesa.

Por aquel entonces, la publicación en revistas o en periódico era muy habitual. Es la razón de que hayamos encontrado pocas ediciones en formato libro, pues resultaba muy caro y arriesgado, mientras que los periódicos eran muy asequibles y constituían una fuente de divulgación literaria, ágil y al alcance de todos. Las cartas, sin embargo, confirman sin género de dudas que se publicaron algunas de las obras de don Benito en periódicos vieneses, traducciones que no hemos conseguido recuperar y de las que no hay rastro bibliográfico en los manuales y artículos consultados.

Ya en nuestro artículo anterior pusimos de relieve que actualmente se están revisando todos estos datos referidos a las traducciones y que el estudio de las traducciones en Francia (López Jiménez 1990, 1993, 1995), sí recogen las traducciones en formato feulletin. En cambio, que nosotros sepamos y tengamos constancia, no existe un estudio similar para las traducciones en lengua alemana. Aunque en nuestro trabajo no nos planteamos la revisión de la bibliografía como eje central, inevitablemente han surgido líneas de investigación secundarias al objetivo central. El estudio de estas cartas ha revelado la posible existencia de traducciones desconocidas por los especialistas, por lo que, aun no siendo objetivo central de nuestro análisis, la bibliografía sobre traducciones publicadas en Austria en vida del escritor deberá ser revisada en artículos posteriores.

Como dato de la existencia de estas publicaciones, debemos aclarar que Galdós respondía a las cartas recibidas. Por lo general, el escritor autorizaba, expresamente, y anotaba a lápiz el sentido de la respuesta. De estas anotaciones y del contenido de las cartas se infiere que el escritor concedió autorización para que se tradujeran en Austria, al menos, las siguientes obras: Doña Perfecta, Miau, El abuelo (adaptación teatral), La mula y el buey y La novela en el tranvía.

En los apartados temáticos que siguen aportaremos los detalles que apuntan hacia la probabilidad de que en vida de Galdós se tradujeron y publicaron alguna de las obras anteriores.

\subsection{Doña Perfecta}

La novela se publica en España en 1876. En Alemania, se editan dos ediciones en vida del escritor: la primera en 1886 y la segunda en 1903. Se conservan 
numerosas cartas de candidatos alemanes a traducir esta novela, sin embargo, en Austria solo hemos encontrado a un corresponsal interesado en traducirla. Se trata de Hugo Kosterka (checo), que escribe, el 12 de enero de 1891 (carta número 64), una larga carta redactada en español. En ella le dice que ya ha tenido el honor de traducir otras novelas, concretamente, algunas de Emilia Pardo Bazán. Traslada a Galdós que escribe desde su patria, Bohemia, y que comparte con el escritor su lucha política por la emancipación de las mujeres, etc. Desea dar a conocer la literatura española y se siente muy identificado con los personajes de Doña Perfecta:

Yo, un joven aun, he complacídome en el amor de la libertad y de progresso [sic] (el quién manifestase en ese roman [sic] de Ud., muy señor mío) y ese placer, supongo que hallarán también nuestros lectores en nuestra lucha política. También nosotros, estudiantes en nuestro tiempo de reformación, combatimos en nuestra revista [sigue título en checo ilegible], por esas ideas y por ideas de emancipación de las mujeres y de los obreros, las quales declaramos también en nuestra biblioteca [sigue título en checo] Bibliotheque de l'enseignement), en la qual quería yo también incluir el muy honrado nombre de Ud., muy illustre señor, junto a otros corifeos de modernas literaturas.

El remitente cita como autores ya traducidos e incluidos en esa colección a Tolstoi, a Stuart Mill y menciona que están en preparación algunas obras de “ilustre señora Doña E. Pardo Bazán". El escritor anota a lápiz: "autorizado". No se especifica en la carta si pretende traducir al checo o al alemán.

\subsection{Miau}

Se publica en España en 1888. En la correspondencia que el escritor mantiene con traductores en Alemania no se conserva ninguna carta que manifestara la voluntad o el interés de traducir esta novela. Tampoco queda rastro documental de que se haya traducido en vida del autor. En cambio, en la correspondencia austríaca hemos encontrado a un traductor, José Siebenlist, que se dirige, por primera vez, al escritor en una carta fechada el 5 de septiembre de 1891 (carta número 72) en español. Es una carta que, por su brevedad e interés, nos permitimos transcribir aquí:

Muy Señor mío: Un modesto escritor Austriaco, admirador de su ingenio le pido a Ud. el favor de concederme la autorización para la traducción alemana de su no- 
vela Miau. En mismo tiempo le pregunto a Ud. cual es la obra que Ud. preferiría ver traducida en alemán?

Me despido suyo attmo. s.s.q.b.s.m. José Siebenlist.

Viena, VII. Kaiserstrasse 6

Hemos transcrito la carta con sus errores de estilo y de gramática, pues es un documento original y valioso de una época. En general, las cartas que recibirá Galdós pidiendo autorización para traducir sus novelas contienen, con ligeras variantes, lo que solicita Siebenlist en la suya. En estas misivas, quienes se dirigen por carta al escritor se ofrecen para traducir una novela determinada, pero quedan a disposición del autor para que él sugiera otra de su elección. En esta carta remitida a Galdós con la petición de traducir Miau, figura a pie de página una anotación a lápiz de don Benito en la que se lee "autorizado el 15 de set. 91", lo que significa que Siebenlist obtuvo la autorización del escritor para traducir Miau.

Siebenlist vuelve a escribir el 9 de enero de 1894 (carta número 76). Nótese que han transcurrido casi tres años desde la primera carta. No se conservan cartas de este corresponsal de entre los años 1891 a 1893; es posible que hayan existido, pero no figuran en el archivo personal del escritor. En esta nueva misiva le recuerda que ya hace dos años que había recibido la autorización para traducir Miau. Le informa de que no consigue despertar el interés de los editores para publicar su traducción en formato libro, pero que el periódico "Neue Freie Presse” sí lo hará:

Los libreros-editores no queriendo dar a luz mi traducción, con mucha pena he logrado, que la "Nueva Prensa libera" ("Neue freie Presse") de Viena, el órgano mas estimado de la prensa Austríaca y Alemana, ha declarado que quiere publicar la dicha traducción en su folletín, lo que sería de mucho más provecho para el nombre de Ud. en Austria y Alemania. Y entonces los editores no tardarán publicarla también como libro y sería fácil publicar traducciones de otras novelas más.

En aquella época, la prensa funcionaba como divulgadora de literatura, estaba mucho más activa y publicaba en forma de suplemento literario o folletines, la obra de los autores del siglo XIX; esto permitía que la literatura llegara a un público más amplio y que su difusión fuera mayor (García Pinacho 2016).

Siebenlist vuelve a escribir el 9 de mayo de 1894 (carta número 74). Nótese de nuevo que el orden digital no se corresponde con el cronológico. En el archivo figura como carta número 74, mientras que la anterior es la carta 
número 76. Es un dato sin importancia, pero que explica el motivo por el cual hemos preferido hacer una estructura temática propia. En esta nueva carta solicita datos biográficos del autor. Era una práctica habitual que acompañando a la traducción se ofreciera a los lectores una semblanza biográfica y literaria del escritor. Siebenlist va a publicar la obra en el periódico "Neue freie Presse", en Viena y ruega a Galdós que tenga la amabilidad de facilitarle algún dato que le permita redactar estas breves líneas biográficas a los lectores vieneses.

Esta carta es la última de Siebenlist que se conserva en el archivo de la Casa-Museo Pérez Galdós y en la despedida felicita al autor por el éxito de $\mathrm{La}$ de San Quintín.

\subsection{La de San Quintín}

Se publica en España en 1894. En el caso de Alemania, la traducción y representación de esta obra de teatro despertó el interés del director del Residenz Theater de Berlín y culminó con un contrato entre Galdós y el director, Sigmund Lautenburg. Sin embargo, en la correspondencia recibida desde Austria, solo hemos encontrado una epístola en la que se manifiesta la voluntad y el deseo de traducir dicha obra teatral.

La carta lleva la firma de N. Birnbaum y está fechada el 7 de agosto o de abril de 1895 (carta número 21). Esta escrita en francés y en ella, el autor le comunica que ha disfrutado enormemente con la comedia La de San Quintín, y le pide autorización para traducirla. Le asegura que posee las dotes literarias suficientes como para abordar la tarea y le anuncia que si contesta afirmativamente puede moverse en la escena teatral para que la obra sea representada, y con suerte puede que llegue a tiempo para que sea representada en la temporada actual. Le explica que no habla español, pero que lo entiende perfectamente y anima a Galdós a que le escriba en español. No se conservan más cartas en el archivo de esta persona.

\subsection{El abuelo}

El abuelo se publica en 1897 en España. Esta obra despierta el interés traductor de Richard Fleischner. Escribe a Galdós el 4 de enero de 1898 (carta número 28) en un español casi perfecto. Se declara entusiasmado al haber terminado la lectura de El abuelo: 
Ahora que conozco tan magistral obra, deseo darla a conocer al público alemán y le ruego a Ud. me conceda la autorización exclusiva para la traducción de "El abuelo" en lengua alemana en las condiciones que Ud. estime convenientes.

Se presenta como redactor del periódico "Revista semanal de economía política" ("Volkswirtschaftliche Wochenschrift") en Viena y le informa de que colabora también con una entidad bancaria española, sita en la calle Espoz y Mina 17, en Madrid. Comenta que tiene experiencia acreditada como traductor y cita algunas obras traducidas por él y aprovecha para pedirle un favor: que escriba el prólogo para la edición alemana de El abuelo.

Galdós le contesta el 8 de enero de 1898, dato que extraemos de la carta que Fleischner le dirige con fecha 26 de enero de 1898 (carta número 30). En algún momento de esta relación epistolar, el escritor debió comentar que Fastenrath, ilustre hispanista alemán muy conocido en su tiempo, estaría interesado en la traducción de dicha obra. Fleischner quiere saber si esa traducción se va a materializar o no, para que él pueda verse favorecido con la autorización de don Benito. Esta persona recibe con regularidad el diario madrileño El Imparcial, pues comenta:

Por El Imparcial supe que estaba Ud. haciendo un arreglo de la novela susodicha para el teatro y espero impaciente que Ud. lo concluya para saborear un drama nuevo de pluma tan experta como lo es la del autor de Gloria, Realidad etc. Gustosamente emprenderé la traducción al alemán, ya que tenemos por aquí a unos cuantos actores que pueden competir ventajosamente con Novelli, al que se admira aquí en lo mucho que vale.

Suplico pues a Ud. se digne contestarme acerca del Sr. Fastenrath y créame Ud. su más sincero admirador.

Fleischner escribe de nuevo el 20 de febrero de 1898 (carta número 32) suplicando una autorización para traducir El abuelo. Entre líneas podemos deducir que Galdós ha concedido algún tipo de autorización a Fastenrath para que traduzca la novela. En cambio, y según se deduce de la nueva carta de 22 de mayo de 1898 (carta número 34) de Fleischner, parece que don Benito le concede la traducción de la versión teatral porque comenta:

Su última carta me hizo concebir la halagüeña esperanza que para fines de Marzo recibiría yo el arreglo teatral de su preciosísima novela El Abuelo.

Impaciente ya por poner manos a la obra, me permito recordarle su amable promesa y le ruego haga remitirme el tan deseado manuscrito, al cual dedicaría los 
meses de verano; creo que entonces, si consigo llevar a cabo tan difícil cometido y me resulta bien el trabajo, podría representarse El Abuelo en la próxima temporada teatral.

Hasta aquí llega la correspondencia relativa a la novela y el arreglo teatral de El abuelo. Fleischner volverá a cartearse con Galdós, esta vez para solicitar la traducción de la obra Alma y vida, asunto que trataremos más adelante.

\subsection{Electra}

Es un drama que se estrena en el Teatro Español el 30 de enero de 1901. Tuvo una enorme resonancia en Europa y los teatros querían ponerla en escena. Para ello debían, primero traducirla a los respectivos idiomas y luego pasar el filtro de la censura. La primera traducción se realiza por parte de Rudolf Beer, y se publica en el Wiener Verlag, es decir, en Viena. El director del Deutsches Volkstheater de Viena, Emérich von Bukowis, inicia una correspondencia con el autor para conseguir los derechos de traducción y de representación teatral.

Lo primero que se conserva es un telegrama de don Benito dirigido al director del teatro. Está escrito en francés, pero no consta fecha en él. Se trata del documento o carta número 22 del archivo digital y dice lo siguiente: "Je vous accorde droit exclusif pour traduction et représentation Electra en Autriche et Allemagne. Condition suivent par lettre. Galdós”.

Entendemos que el telegrama es anterior a la secuencia de cartas que se conservan en el archivo escritas por el director. Como avisábamos en otros apartados, el archivo digital no ha respetado el orden cronológico y así ocurre que el orden digital no se corresponde con el cronológico. En cualquier caso, nosotros hemos ordenado dentro de cada obra cronológicamente las diferentes cartas y referenciado el orden digital entre paréntesis.

La primera de las cartas está fechada el 2 de febrero de 1901 (carta número 2) está redactada en alemán y no está dirigida al escritor. El director se cartea con un colega no identificado en la carta y expone los pormenores técnicos relativos a la traducción y derechos de la representación de Electra. La obra se estrenó en España un 30 de enero de 1901 y está carta es de 1 de febrero, por lo que sorprende la velocidad a la que Bukowis inicia contactos con Galdós, ya que el telegrama del escritor responde a una petición de parte del teatro en Viena para conseguir los derechos. Esa carta o telegrama anterior del teatro no se conserva, pero debió recibirse en enero. Tampoco contamos con la fecha precisa de publicación de Electra en alemán, pero sí el año de la 
traducción de Rudolf Beer que es de 1901, es decir, coetánea a las cartas del director.

La segunda de las cartas (no se lee bien la fecha), parece que está datada el 17 de abril de 1901 (carta número 6) y está escrita en francés. En ella el director se dirige a Galdós para decirle que ha aprovechado el mismo paquete de correo para enviarle los ejemplares de la traducción de Electra, tanto para las librerías como para su puesta en escena en el teatro. Además le informa de que "lédition de théâtre est envoyé en même temps a tous les théâtres Allemandes et Autrichiens". Al parecer, tienen ciertos problemas relativos a la elección de la sala de teatro donde se podría representar, en Hungría. Le advierte de que la censura sigue en sus trece, pero que ellos confían en poder poner en escena la obra en otoño. En la misma misiva agradece un envío que se dirige al señor Berger. Ignoramos si se trata del traductor vienés de igual nombre que también se pone en contacto con Galdós, interesándose por la traducción de Sor Marcela y del que se hablará más adelante. Nos faltan datos para asegurarlo, aunque todo apunta en ese sentido.

La tercera de las cartas está fechada el 29 de abril de 1901 (carta número 8), redactada en francés. De nuevo, tenemos dudas en cuanto a la fecha, pues no se lee bien. En cualquier caso le indica que la versión teatral de Electra la tienen programada para la temporada próxima, porque "la censure n’a pas encore libérée la pièce et nous demande des changements assez important [...]". Es la primera vez que se menciona el activo papel de la censura en Austria con relación a la obra Electra y el director teme que al final no se pueda estrenar en Viena.

La cuarta y última de las cartas conservadas está fechada el 26 de octubre de 1901 (carta número 4) y está redactada en francés como las demás. La censura no ha permitido el estreno en el Deutsches Volkstheater: "Electra est irrévocablement défendu par la censure. Je regrette de ne pas pouvoir vous donnes des meilleures nouvelles pour l'instant". Le comenta que están en contacto con el ministro, pero que no se hacen ilusiones del resultado de estas conversaciones. Parece que los obstáculos interpuestos por la censura resultaron insalvables y lamenta que no se pueda representar. Hasta aquí llega la correspondencia con el director del Deutsches Volkstheater de Viena.

La traducción que se conserva de Electra es la de Rudolf Beer, como ya hemos detallado, pero otra persona escribió a don Benito con el firme deseo de traducir la obra. Se trata de Laura von Feibelson. Esta traductora se dirige en francés a Galdós el 11 de marzo de 1901 (carta número 26). Esta carta contiene datos que la convierten en un testigo y un referente histórico de 
los eventos que hemos relatado sobre la versión teatral para Austria y Alemania. La corresponsal sabe que la obra se representará en fechas próximas en Viena:

Comme jai lu, que la pièce sera représentée en quelque temps ici à Vienne (Autriche), je vous demande Monsieur, si vous voudrez avoir l'amabilité de me donner votre autorisation à traduire votre belle pièce sous forme de livre e a' la faire représenter en Allemagne.

Las condiciones contractuales en el mundo de la traducción no son objeto de estudio en nuestro trabajo, pero constituyen una línea de investigación que dejaremos para artículos futuros; más bien esta carta revela que era inminente el estreno de Electra en Austria, y que era muy esperada. Informa al autor de que está al corriente de que pronto será escenificada en Viena. Si nos fijamos en la fecha en que está escrita la carta, comprobamos que en marzo aun no se había pronunciado la censura. Laura von Feibelson se despide del escritor y le pide también autorización para traducir Misericordia. No consta respuesta de don Benito siendo esta además la única carta de la señora Feibelson que se conserva en el archivo.

Existe una carta más, cuya remitente es una señora que firma como Louise Lucca que también manifiesta su interés por traducir Electra. La carta está fechada un 3 de marzo de 1901 (carta número 66). Le indica que también desearía traducir su colección de cuentos en alguno de los periódicos de primera línea, tal y como ya hiciera con los cuentos de doña Emilia Pardo Bazán. No existen más cartas de esta corresponsal.

\subsection{Sor Marcela}

Richard Berger remite un total de tres cartas, todas ellas redactadas en francés. Pero antes de analizar las carta hemos de aclarar que en la bibliografía de Pérez Galdós no existe novela alguna que se titule Sor Marcela. En realidad se trata del título que se dio en Francia a uno de los Episodios nacionales traducido y publicado en un diario muy importante de la época como fue $L e$ Temps. Este diario fue también muy activo en noticias sobre Galdós (García Pinacho 2016). El título original en español es La campaña del Maestrazgo (1899), pero en su versión francesa se publicó bajo el título de Sor Marcela (Etienvre 1976: 124): 
En 1901, Le Temps publiera, également en feuilleton, La Campaña del Maestrazgo, sous le titre de Le Roman de Soeur Marcela, dans une traduction de La Grange de Langres; cette traduction paraitra en volume, en 1902, chez Calmann-Lévy.

La primera está fechada el 11 de diciembre de 1901 (carta número 14). Esta carta de Berger va dirigida, en realidad, al director de un diario vienés y solicita que le permitan publicar en alemán la traducción de la novela Sor Marcela del escritor Pérez Galdós. Les asegura que no tendrán queja sobre la calidad de la traducción: "En cas, que je reçoive votre permis [...] J’espère que la traduction réussira à votre contentement. [...] et à celui de M. l'auteur".

El corresponsal se adelanta al escribir a la redacción del periódico, pues aún no cuenta con la autorización del propio escritor, pero a pie de página comenta que ha solicitado también el permiso para traducir la obra a don Benito en otra carta.

La siguiente carta es de 27 de diciembre de 1901 (carta número 16). En ella Berger informa que ha recibido la respuesta de Galdós y añade que tiene pensado realizar la traducción al alemán a partir de la traducción francesa, pues lamenta mucho no dominar lo suficientemente el español. Se estipula también el plazo de traducción que desea ampliar y que una vez concluida la traducción hablará con la redacción y con don Benito del tema de los derechos de autor y su abono. Galdós anota a lápiz lo siguiente: "1 de Enero: doy dos meses de plazo para hacer trato definitivo".

La última de las cartas de Berger está datada el 22 de febrero de 1902 (carta número 18). En ella se lamenta de no haber podido convencer a los diarios vieneses para que publicaran su traducción, por lo que debe renunciar al derecho de traducción otorgado por el escritor.

\subsection{La mula y el buey}

Se publica en España en 1876. Se conservan en el archivo un total de doce cartas que remite Ellen Goldenberg a don Benito. La primera de ellas está fechada el 23 de octubre de 1901 (carta número 40), en un perfecto español. La autora de la misiva desea traducir cuanto antes el relato La mula y el buey, para publicarlo en Navidad. Del contenido de la carta se deduce que no era la primera vez que escribía a Galdós con esta petición:

Yo algunas veces he tomado la libertad de escribir a Ud. para su autorización de publicar una traducción de su bellísimo cuento de Navidad La mula y el buey. Espero que la contestación favorable que no he recibido hasta ahora estará dada esta vez 
y le ruego a Ud. Señor de dármela muy de priesa, pues números de Navidad ya están preparados.

La siguiente carta está fechada el 14 de noviembre de 1901 (carta número 42) y le reitera que espera ansiosa la autorización para publicar ese cuento, pues lo va a publicar en la "Neue freie Presse":

Dispense Ud. mi impaciencia en esperar ya quince días su contestación que me permita de publicar mi traducción de La mula y el buey en la "Neue freie Presse" y como los números de Navidad ya se preparan le ruego mucho a Ud. señor de hacerme el favor de enviarme su preciosa autorización el más pronto posible.

Ellen Goldenberg, según se desprende de sus cartas, es una persona diligente e insistente, inasequible al desaliento. Cada una de las cartas que escribe se caracteriza por su firme voluntad encaminada a conseguir la autorización para traducir las obras de Galdós y no se desanima por la falta de respuesta.

La siguiente está fechada el 14 de diciembre de 1901 (carta número 44), es decir, ha transcurrido un mes desde la anterior. En ella se aprecia la repercusión que supuso el estreno de Electra en Europa:

Todos los círculos literarios aquí tienen grandísimo interés para el autor de la Electra y las redacciones de la revista "Die Zeit" y del más notable papel [quiere decir periódico] austriaco "Neue freie Presse" tendrían gran gusto de publicar algunas obras de Ud. Tal vez que tendría Ud. la bondad de enviarme algunas novelas (cortas o un Essay interesante con la autorización de traducirlas al alemán. La "Zeit" tendría gran gusto, si Ud. querría escribir para ella un artículo sobre la literatura española de los últimos años y de su estado actual.

Le informa de que el artículo no debe superar las 2.600 palabras. Esta carta contiene a pie de página una interesantísima anotación de don Benito que nos permitimos transcribir literalmente:

Que le agradezco mucho sus frases lisonjeras. "La Neue frei Presse" y "Die Zeit" pueden hacerme las proposiciones que gusten, pero a causa de tener ahora ocupaciones excesivas no me será fácil complacerles hasta pasado algún tiempo. No tengo novelas cortas. Las de uno o dos volúmenes pueden ser publicadas en alemán, si se halla un traductor nativo... me congratulo de entrar en relaciones con este señor.

Ellen Goldenberg le vuelve a escribir un 1 de enero de 1902 (carta número 46). En esta misiva retoma la cuestión del artículo que la revista "Die Zeit" 
estaría interesada en publicar. De nuevo le solicita una respuesta, espera que favorable a su petición.

La siguiente es de 6 de enero de 1902 (carta número 48), es decir, apenas cinco días más tarde. Ellen Goldenberg por fin ha recibido la tan ansiada respuesta:

Muchas gracias para su amabilísima contestación que he recibido con gran placer. Delante todo tengo que repetirle a Ud. cuanto valor tiene para la revista "Die Zeit" su cooperación y que le ruego insistentemente de escribir el artículo sobre la literatura española.

La siguiente es de 18 de agosto de 1902 (carta número 50). En ella, Ellen Goldenberg, le informa de que ha traducido un cuento de Navidad, y le ruega que le dé su autorización para publicarlo.

He traducido al alemán su delicioso cuento de Navidad La mula y el buey que he leído en el "Nuevo Mundo" y ahora vengo rogarle a Ud. de darme su preciosa autorización para publicarlo en un número de Navidad de uno de nuestros grandes periódicos, tal vez "Neue freie Presse" cuyo redacteur ya me pide repetidamente una de sus obras.

Continúa la carta en un tono de apremio, porque los números de Navidad ya se están preparando y por eso urge la autorización cuanto antes, y le dice: "Me siento mucho que debo darle este incomodo a Ud., pero creo que también a Ud. puede ser agradable de estar leído en Viena, donde tienen mucho interés para el autor de Electra".

Se deduce de esta carta la repercusión de Electra en Europa y también el prestigio de que gozaba Galdós, pues el director del periódico ansía publicar en alemán cualquier obra del escritor. Por eso Goldenberg insiste en que le sugiera algún título apto para ser traducido y publicado en prensa, como pueden ser novelas cortas, porque dice "trabajo mucho para revistas y periódicos".

La siguiente es de 19 de febrero de 1904 (carta número 52). Ha transcurrido un año y medio desde la carta anterior. Ellen Goldenberg le refresca la memoria a Galdós y le recuerda que fue ella la que había publicado su cuento La mula y el buey:

Ud. se acuerda tal vez que el año pasado he traducido al alemán su cuento de Navidad La mula y el buey para la "Neue freie Presse". Hoy vengo, Señor, para preguntarle a Ud. si quiere enviarme su nuevo drama, que estaba representado ahora con 
así gran suceso [éxito]. Yo querría traducirlo al alemán y creo los teatros alemanes serían [palabra ilegible] a representar una obra suya.

Ellen Goldenberg y sus cartas revelan que La mula y el buey apareció publicada en la prensa vienesa en 1903 y que los austriacos estaban informados de los éxitos teatrales y literarios de Galdós y se interesaban en darlos a conocer en Austria y en Alemania.

La siguiente está fechada el 23 de febrero de 1904 (carta número 54), apenas una semana después de la anterior y viene a confirmar lo que dijimos sobre esta corresponsal: su determinación e insistencia para conseguir la autorización del escritor. En esta ocasión escribe y le comenta que:

[... ya habrá recibido el mío telegrama y espero Señor que ya habrá decidido a autorizarme a traducir la drama El Abuelo que seguramente tendrá en Alemán un gran suceso como en Español. Estoy en muy buenas relaciones con los teatros de Viena y también en las escenas Alemanas. Puedo contribuir a la representación. Le ruego mucho Señor de dejarme porvenir su contestación muy depriesa y sería muy feliz de tener el honor y el placer de traducir otra vez una de sus obra.

La siguiente está fechada el 12 de marzo de 1904 (carta número 56). Han pasado unas escasas dos semanas desde la anterior y, dado que no ha obtenido respuesta ni a su telegrama ni a su carta, le insiste para que conceda su autorización para traducir El abuelo, en concreto la versión para teatro, pues continúa diciendo: "Yo estoy en las mejores relaciones con el director del Volkstheater aquí y estoy segura que también los otros teatros alemanes pasan a representar su obra”.

La siguiente carta está fechada el 24 de abril de 1905 (carta número 58) y en esta ocasión no reclama ningún ejemplar de El abuelo o la autorización para traducirla, sino que le pide "un feuilleton sobre el Don Quijote, un tema que tiene gran interés para el público ahora". Se refiere a que le mande un artículo sobre el tema de Don Quijote para que se publique en el feuilleton, o suplemento literario de algún periódico cuyo nombre no indica. De nuevo encontramos en estas cartas pruebas de que seguramente existan traducciones y colaboraciones de Galdós en prensa vienesa. Es una línea de investigación que investigaremos en artículos posteriores.

La siguiente carta no tiene fecha (carta número 60), pero se refiere esta vez a cartas anteriores que no han sido respondidas por Galdós. Insiste en que le permita publicar su traducción alemana de La novela en el tranvía y como argumento a su favor dice: 
Si Ud. quiere dármela tendré mucho gusto y como Ud. ya ha tenido la bondad de dármela para La mula y el buey que tenía mucho suceso [éxito] en alemán yo espero que también esta vez Ud. querrá cumplir mi deseo.

En la carta de 19 de febrero de 1904, Ellen Goldenberg ya le había refrescado la memoria a don Benito y le había recordado que había publicado ese cuento en la "Neue freie Presse", pero por si cabía alguna duda con relación a la autorización por parte de don Benito, aquí tenemos la prueba de que el escritor autorizó y conoció de la publicación de La mula y el buey en Viena. En la bibliografía que hemos manejado no aparece ese dato que habrá que revisar y documentar en estudios posteriores.

La siguiente tampoco tiene fecha (carta número 62), ahora bien es un sólido testimonio de la actividad traductora de Ellen Goldenberg y de la publicación de las obras de Galdós en la prensa vienesa; es la última carta que se conserva de esta traductora.

\section{Muy Señor mío:}

Tengo mucho placer a decirle a Ud. que mi traducción de la Novela en el tranvía será publicada en la "Neue freie Presse". Pues Ud. puede ver que el juicio tan severo que Ud. mismo ha pronunciado en su carta que este trabajo sea infantil, era exagerado y que la novela tan humorística puede interesar al público, ¡sobre todo cuando está firmado Galdós! Me permito de repetir mi gusto de traducir de Ud. un "essay", también cuentos si Ud. tiene algo de este género.

Le ruego mucho a Ud. señor de no negarme este gusto y esperando el favor de su contestación suplico, reciba entretanto la seguridad de mi más alta consideración con la que quedo de Ud. afma. Fdo.: Ellen Goldenberg.

\subsection{Alma y vida}

Es un drama que se estrena en el Teatro Español el 9 de abril de 1902. El corresponsal, Richard Fleischner, que se había interesado anteriormente por traducir El abuelo, se pone en contacto, nuevamente, con don Benito. Le escribe el 21 de enero de 1902 (carta número 36), como siempre en un correcto español. Comenta que ha leído en El Imparcial que se va estrenar esa obra y solicita el derecho de traducirla al alemán y le dice que está convencido que la censura no impedirá esta vez su representación. No sabemos a ciencia cierta a qué se refiere, pero muy probablemente y por las fechas en las que escribe estemos hablando de Electra y su fallido estreno en Viena. 
[...] tendré buen cuidado de sujetar al director del teatro que solicite de mi el derecho de representar Alma y vida. La parte material de este asunto se arreglará a la conveniencia de Ud. Teniendo yo compromiso formal con Ud., ya sabré impedir que se cometa un crimen de lesa literatura, cual el perpetrado en Hamburgo y del cual tiene Ud. noticia por el artículo de Mariano de Cavia.

[...] En cuanto a El Abuelo tengo la satisfacción de anunciarle que voy muy adelantado con la traducción, no exenta de dificultades por causa del carácter local de gran parte de la acción.

De esta carta, extraemos, dos datos: que don Benito otorgó efectivamente, el derecho de traducción de El abuelo a Fleischner, y que igualmente le autorizó a traducir Alma y vida. En lo que se refiere a la autorización para traducir El abuelo resulta cuanto menos curioso que Ellen Goldenberg también la solicitara en 1904. Si Galdós la había otorgado a Fleischner dos años antes y en esta carta le informa de que está muy avanzada la traducción debemos preguntarnos si se publicó también. No conservamos más cartas de Fleischner por lo que ignoramos si Alma y vida fue publicada en Austria o no.

\subsection{Nazarín y Marianela}

Alfredo Penizek escribe una carta, fechada en 1908 (carta número 68) y redactada en español. Solicita del escritor autorización para traducir estas dos novelas y dice:

He leído con sumo interés sus dos romanes Nazarín y Marianela y desearía traducirlos al Alemán para publicarlos en un periódico de esta capital y en forma de libro para lo cual tendría que tener su permiso. Al mismo tiempo ruego a Ud. me de su benévola autorización para las cosas pequeñas que casualmente estoy leyendo.

Es la única carta que se conserva de esta persona. No sabemos si obtuvo, finalmente, la autorización de Galdós.

\subsection{Miscelánea}

Mizi Franzos, escribe al escritor una carta fechada el 26 de abril de 1896 (carta número 38) en francés. Esta persona no elige una obra en particular, no solicita derechos de traducción para ninguna novela concreta. Es un caso frecuente que se observa en las cartas de algunos corresponsales, que deseaban 
publicar en alemán obras de Galdós y dejaban al escritor la elección de la obra. Franzos le comenta que ya ha traducido algunas obras de Emilia Pardo Bazán para el periódico "Die Zeit" y solicita autorización para traducir cualquier relato o novelita que guste el autor.

Otra de las cartas remitida desde Austria pertenece a Frederic Bank y está fechada un 2 de noviembre de 1903 (carta número 10) redactada en francés. El corresponsal se presenta como socio de la Akademische Union de Viena, le informa de los objetivos de dicha sociedad, en particular de la educación e ilustración de los pueblos, y le solicita su permiso para nombrarle miembro honorífico en la sesión que se celebrará el próximo 20 de noviembre.

En el archivo se conserva una carta muy singular, escrita por Santo Selmo, el 12 de julio de 1910, remitida desde Constantinopla (carta número 70). En ella le comunica que le envía un ejemplar de un drama histórico, escrito por él, titulado Don Isaac. Solicita la ayuda de don Benito para vender esa obra en España y le ofrece un porcentaje por anticipado. La posdata es muy interesante, y la transcribimos completa, respetando sintaxis y ortografía originales: "El idioma en el que le escribo es el que llamamos "judío español". Ud. me dispensará si es algo diferente del castilliano, pero espero que Ud. ya lo comprehenderá el mismo".

Es decir, se trata de un judío sefardí y si bien la carta no está relacionada con el mundo de la traducción que investigamos en este artículo, la hemos incluido porque figura dentro del archivo de cartas escritas desde Austria, ya que el matasellos es austriaco. Ahora bien, curiosamente, en el encabezado el remitente anota "Santo Selmo. Constantinopla". La carta tiene, desde nuestro punto de vista, un interés historiográfico.

\section{Conclusiones}

El análisis histórico-traductológico de la correspondencia entre Galdós y sus traductores austriacos ha aportado algunos datos nuevos. Hemos detectado la existencia de traductores desconocidos que, según se infiere de las cartas, publicaron algunas de las obras de Galdós. Esas traducciones se difundieron a través de la revista "Die Zeit" y del periódico "Neue freie Presse" de la ciudad de Viena, que publicaron en vida del autor alguna de sus obras. Los investigadores de las traducciones al francés (López Jiménez 1990, 1993, 1995), sí que recogen las traducciones en formato feulletin y han estudiado, paralelamente, la publicación en libro de alguna de las obras de don Benito. En el siglo XIX y XX, coexistía la publicación de libros por parte de edito- 
riales, con la publicación de literatura en periódicos o suplementos literarios habituales de la prensa escrita. Gran parte de la investigación realizada sobre la obra traducida al alemán en época del escritor, recoge la obra publicada en libro, es decir, en editoriales. Sin embargo, no se han investigado suficientemente, las traducciones al alemán publicadas en aquella época en revistas o periódicos, tal y como sí se ha hecho con las traducciones al francés. En general, se prefería por parte de los escritores, iy de los traductores!, la publicación en prensa, porque este medio de divulgación permitía llegar a los lectores la literatura a un coste muy económico. En cambio, en las traducciones realizadas con editoriales, los traductores corrían con los riesgos de un fracaso editorial y muchas veces se arruinaban, por no hablar del coste para los posibles lectores que compraban esos libros, puesto que también era más elevado que el de un periódico. Es una línea de investigación que sería interesante iniciar, pues del estudio realizado llegamos a la conclusión de que, al menos, dos medios de prensa escrita vieneses, publicaron parte de la obra de Galdós.

Asimismo, queda por dilucidar si las piezas teatrales traducidas fueron o no representadas en vida del autor en el Imperio Austrohúngaro. Es una pregunta que surge de los datos que se extraen de las cartas analizadas. Sabemos, por ejemplo, por las cartas de Bukowis, director del teatro nacional de Viena (Deutsches Volkstheater), que el estreno de Electra en Viena no fue posible en las fechas previstas, debido a los problemas que tuvo esa obra con la censura. Las cartas entre Galdós y sus traductores han resultado ser una fuente inestimable de datos históricos que nos han revelado la existencia de obra traducida que aún no ha sido descubierta. Nuestro objetivo central iba encauzado a realizar un análisis histórico- traductológico del interés de la obra de Galdós, en Europa, a través de esas cartas. Entendemos que nuestro objetivo ha quedado probado por el interés demostrado por los corresponsales, que son testimonio de que Galdós era conocido y apreciado más allá de las fronteras de España. Utilizar los epistolarios como fuente de información histórica ha resultado una herramienta eficaz para abordar diferentes ámbitos del mundo literario y traductológico en torno a la figura del escritor. 


\section{Traducciones en Austria en vida del autor}

Pérez Galdós B., 1901, Electra, trad. R. Beer, Viena.

\section{Relación de cartas consultadas y comentadas}

Bank F., 1903, Carta número 10, de 2 de noviembre de 1903, Casa-Museo Pérez Galdós.

Berger R., 1901, Carta número 14, de 11 de diciembre de 1901, Casa-Museo Pérez Galdós.

Berger R., 1901, Carta número 16, de 27 de diciembre de 1901, Casa-Museo Pérez Galdós.

Berger R., 1902, Carta número 18, de 22 de febrero de 1902, Casa-Museo Pérez Galdós.

Birnbaum N., 1895, Carta número 21, de 7 de agosto (o abril) de 1895, Casa-Museo Pérez Galdós.

Bukowis E., 1901, Carta número 2, de 2 de febrero de 1901, Casa-Museo Pérez Galdós.

Bukowis E., 1901, Carta número 6, de 17 de abril de 1901, Casa-Museo Pérez Galdós.

Bukowis E., 1901, Carta número 8, de 29 de abril de 1901, Casa-Museo Pérez Galdós.

Bukowis E., 1901, Carta número 4, de 26 de octubre de 1901, Casa-Museo Pérez Galdós.

Feibelson L., 1901, Carta número 26, de 11 de marzo de 1901, Casa-Museo Pérez Galdós.

Fleischner R., 1898, Carta número 28, de 4 de enero de 1898, Casa-Museo Pérez Galdós.

Fleischner R., 1898, Carta número 30, de 26 de enero de 1898, Casa-Museo Pérez Galdós.

Fleischner R., 1898, Carta número 32, de 20 de febrero de 1898, Casa-Museo Pérez Galdós.

Fleischner R., 1898, Carta número 34, de 22 de mayo de 1898, Casa-Museo Pérez Galdós

Fleischner R., 1902, Carta número 36, de 21 enero de 1902, Casa-Museo Pérez Galdós.

Franzos M., 1896, Carta número 38, de 26 de abril de 1896, Casa-Museo 
Pérez Galdós.

Goldenberg E., 1901, Carta número 40, de 23 de octubre de 1901, Casa-Museo Pérez Galdós.

Goldenberg E., 1901, Carta número 42, de 14 de noviembre de 1901.,Casa-Museo Pérez Galdós.

Goldenberg E., 1901, Carta número 44, de 14 de diciembre de 1901, Casa-Museo Pérez Galdós.

Goldenberg E., 1902, Carta número 46, de 1 de enero de 1902, Casa-Museo Pérez Galdós.

Goldenberg E., 1902, Carta número 48, de 6 de enero de 1902, Casa-Museo Pérez Galdós.

Goldenberg E., 1902, Carta número 50, de 18 de agosto de 1902, Casa-Museo Pérez Galdós.

Goldenberg E., 1904, Carta número 52, de 19 de febrero de 1904, Casa-Museo Pérez Galdós.

Goldenberg E., 1904, Carta número 54, de 23 de febrero de 1904, Casa-Museo Pérez Galdós.

Goldenberg E., 1904, Carta número 56, de 12 de marzo de 1904, Casa-Museo Pérez Galdós.

Goldenberg E., 1905, Carta número 58, de 24 de abril de 1905, Casa-Museo Pérez Galdós.

Goldenberg E., n.d., Carta número 60, Casa-Museo Pérez Galdós.

Goldenberg E., n.d., Carta número 62, Casa-Museo Pérez Galdós.

Kosterka H., 1891, Carta número 64, de 12 de enero de 1891, Casa-Museo Pérez Galdós.

Lucca L., 1901, Carta número 66, de 3 de marzo de 1901, Casa-Museo Pérez Galdós.

Penizek A., 1908, Carta número 68, n.d. de 1908, Casa-Museo Pérez Galdós. Pérez Galdós B., Carta número 22, n.d., Casa-Museo Pérez Galdós.

Siebenlist J., 1891, Carta número 72, de 5 de septiembre de 1891, Casa-Museo Pérez Galdós.

Siebenlist J., 1894, Carta número 74, de 9 de mayo de 1894, Casa-Museo Pérez Galdós.

Siebenlist J., 1894, Carta número 76, de 9 de enero de 1894, Casa-Museo Pérez Galdós.

Semo S., 1910, Carta número 70, de 12 de julio de 1910, Casa-Museo Pérez Galdós. 


\section{Bibliografía}

Bly P., 2009, Galdós y los críticos europeos, [in:] Actas del Octavo Congreso Internacional de Estudios Galdosianos (2005), Y. Arencibia, M. del Prado Escobar, R. M. Quintana (eds.), Las Palmas de Gran Canaria, pp. 816-832.

Bosch Benítez A., 2020, Estudio de la correspondencia entre Pérez Galdós y sus traductores alemanes, [in:] Traducción y recepción universal de Benito Pérez Galdós: cien años después (1920-2020), Tibón: estudios traductológicos, número 2, Juan Miguel Zarandona (ed.), Las Palmas de Gran Canaria.

Etienvre F., 1976, Galdós en France avant Electra (Notes sur les articles critiques et les traductions. Lettres inèdites de Galdós, Heredia et Zola), "Bulletin Hispanique", 78 (1-2), pp. 99-136.

García Bolta I., 1993, Pérez Galdós fuera de España, [in:] Actas del Cuarto Congreso Internacional de Estudios Galdosianos (1990), vol. II, Las Palmas de Gran Canaria, pp. 45-56.

García Pinacho M. P., 2016, El tiempo de Galdós. Benito Pérez Galdós en los diarios parisinos. Le Temps, "Moenia. Revista lucense de lingüistica \& literatura", 22, pp. 63-99.

Hernández Suárez M., 1972, Bibliografía de Galdós, Las Palmas de Gran Canaria.

Krauße E., 2005, Der Brief als wissenschaftshistorische Quelle, [in:] Der Brief als wissenschaftshistorische Quelle, Monographien zur Geschichte der Biowissenschaften und Medizin, Bd. 8, Olaf Breidbach (ed.), Berlin, pp. 1-28.

López Jiménez L., 1990, A. Germond de Lavigne, primer traductor al francés de B. Pérez Galdós, “El Guiniguada”, 1, pp. 287-296.

López Jiménez L., 1993, Bixio, bienintencionado traductor mediocre de Misericordia, [in:] Actas del Cuarto Congreso Internacional de Estudios Galdosianos (1990), tomo I, Las Palmas de Gran Canaria, pp. 97-107.

López Jiménez L., 1995, Las traducciones de Pérez Galdós en francés, [in:] La traducción, metodología, historia, literatura: ámbito hispanofrancés, F. Lafarga, A. Ribas, M. Tricás (eds.), La Rioja, pp. 157-164.

Ramírez Jáimez A. S., 1993, Crítica alemana sobre la obra de Galdós en el siglo XIX, [in:] Actas del Cuarto Congreso Internacional de Estudios Galdosianos (1990), vol. II, Las Palmas de Gran Canaria, pp. 189-198.

Ramírez Jáimez A. S., 1995, La recepción de la obra de Galdós en Alemania a la luz de las traducciones, [in:] Actas del Quinto Congreso Internacio- 
nal de Estudios Galdosianos (1992), vol. II, Las Palmas de Gran Canaria, pp. 97-107.

Siemers M., 1993, Equivalencia pragmática de la novela Gloria con su traducción alemana del año 1880 del Dr. August Hartmann, [in:] Actas del Cuarto Congreso Internacional de Estudios Galdosianos (1990), vol. II, Las Palmas de Gran Canaria, pp. 245-253.

\section{Benito Pérez Galdós and his Austrian translators: a study of their correspondence Summary}

Pérez Galdós was a well-known Spanish writer who published between 1870 and 1915. He died in 1920. He was a candidate for the Nobel Prize for five long years, but the literary award went to another Spanish writer, Echegaray, in 1904.

Galdós achieved literary recognition in Europe due to the representation of his drama Electra (1901). Some of the most famous theatres in Europe staged this work, while others could not do it because of strict censorship imposed in a given country as it happened in Austria. Pérez Galdós's novels have been translated into practically all languages of the world, including Japanese, Chinese, Polish, and Russian. In this paper we explore the correspondence between the author and some translators in Austria. This is a continuation of the first paper (Bosch Benítez 2020) about the correspondence with German translators.

There are many academic studies about the reception of the translation in such countries as Germany (Ramírez Jáimez 1993, 1995); France (López Jiménez 1990, 1993, 1995), and Great Britain (Bly 2009). Most of the research on Pérez Galdós has concerned the literary reception, construction or critical aspects of his novels in these countries; however, no specific studies have been conducted on the letters themselves. This paper is an attempt to explore the valuable contents of the letters that can shed some light over other political, literary or social aspects, like the existence of the translations of Pérez Galdós's books in Austria that are not registered in the actual bibliography or the changes that censors in Austria imposed on Electra as a precondition of it being staged. Hopefully, our work can help researches find the translations published; hints of their existence can be found in the letters that we have analysed.

Keywords: Pérez Galdós, translators, Austria, correspondence 